\title{
Heart Rate Variability and Urinary Catecholamines from Job Stress in Korean Male Manufacturing Workers According to Work Seniority
}

\author{
Kyoung-Ho LEE ${ }^{1}$, Kijung YOON², Mina $\mathrm{HA}^{3}$, Jungsun PARK ${ }^{4}$, \\ Soo-Hun $\mathrm{CHO}^{5}$ and Daehee $\mathrm{KANG}^{5 *}$
}

\footnotetext{
${ }^{1}$ Integrated Omics Center, Life/Health Division, Korea Institute of Science and Technology, 39-1 Hawolgokdong, Seongbuk-gu, Seoul 136-791, Korea

${ }^{2}$ Department of Occupational Medicine, Kangbuk Samsung Hospital, School of Medicine, Sungkyunkwan University, Seoul 110-746, Korea

${ }^{3}$ Department of Preventive Medicine, Dankook University Medical College, Cheonan 330-715, Korea

${ }^{4}$ Korea Occupational Safety and Health Agency, Occupational Safety and Health Research Institute, Incheon 403-711, Korea

${ }^{5}$ Department of Preventive Medicine, Seoul National University College of Medicine, Institute for Environmental Medicine, SNUMRC, 28 Yongon-Dong Chongno-Gu, Seoul 110-799, Korea
}

Received July 6, 2008 and accepted October 27, 2009

\begin{abstract}
The aim of this study was to evaluate the relationships between job stress and indicators of autonomic nervous system activity in employees of the manufacturing industry. A total of 140 employees from a company that manufactures consumer goods (i.e., diapers and paper towels) were recruited for participation in this study. Job stress was assessed using Karasek's Job Content Questionnaire. Heart rate variability (HRV) was measured using a heart rate monitor, and urinary catecholamines were measured by an HPLC-ECD. Information on demographic characteristics, previous job history, smoking status and alcohol consumption was also collected. Job stress did not have a significant effect on HRV or catecholamines. However, low-frequency HRV was significantly higher in the high-strain group of subjects with a short duration of employment. Low- and high-frequency HRV were higher in the high-strain group than in the low-strain group, but these differences were not statistically significant. The results of the present study indicate that low-frequency HRV was significantly higher in the high-strain group of subjects with a short duration of employment. In addition, the results of this study show that HRV can be used as a potential physiologic indicator of job stress in employees with a short duration of employment.
\end{abstract}

Key words: Job stress, Heart rate variability, Urinary catecholamine, Job content questionnaire

\section{Introduction}

Psychological stress can lead to heart problems, such as myocardial infarction ${ }^{1)}$ and coronary heart disease ${ }^{2)}$. Job stress has been shown to be associated with an increased prevalence of cardiovascular diseases among

*To whom correspondence should be addressed.

E-mail: dhkang@snu.ac.kr

Kyoung-Ho LEE and Kijung YOON contributed equally as first author. industrial workers ${ }^{3)}$. Heart rate variability (HRV) analysis has been proposed as a noninvasive technique for assessing job-related stressors ${ }^{4)}$ and the influence of the autonomic nervous system (ANS) on heart rate ${ }^{5)}$. HRV analysis was also known to be a strong and independent predictor of mortality after acute myocardial infarction ${ }^{6}$. HRV is analyzed in the frequency domain, yielding estimates of spectral power in low-frequency (LF) and highfrequency (HF) bands, as well as the LF/HF ratio. A previous study found that psychological stress was associat- 
ed with an increase in the LF/HF ratio among shipyard workers7). Pagani et al. (1991a) reported that the LFHRV ratio increased when 25 male volunteers were exposed to psychological stress ${ }^{8}$. Studies of job stress in the manufacturing industry, waste incinerator plants, and in hospital settings have also shown that exposure to job stress increases the LF-HRV ratio ${ }^{9)}$.

The levels of plasma epinephrine and norepinephrine have a long history as indicators of cardiac adrenergic activity. A previous study demonstrated the relationships between circulating catecholamines and low-frequency heart rate variability as indices of cardiac sympathetic activity in 34 healthy volunteers under conditions of psychological stress ${ }^{10}$. Previous studies of truck drivers ${ }^{11}$ ) and bus drivers ${ }^{12)}$ evaluated the effects of job-related stress by analyzing the excretion of urinary catecholamines (i.e. epinephrine, norepinephrine and dopamine) during the workday. These studies found that the level of catecholamine excretion was higher during the workday than at baseline. However, van der Beek et al. (1995) found that the only association between the rate of urinary catecholamine excretion during the workday and work stressors was found for norepinephrine and physical workload ${ }^{11}$.

Studies investigating the relationship between job stress and ANS activity are very limited in Korea. Furthermore, very few studies have investigated the relationship between work-related stress and catecholamines. The hypothesis of this study is that job stress is associated with autonomic nervous system activity in Korean workers as a predisposing factor to cardiovascular disease. Thus, this study was conducted to evaluate the relationship between job stress and ANS activity in Korean workers by measuring the levels of urinary catecholamines and HRV, which are sympathetic/parasympathetic nervous activities that have been suggested to play a major role in the development of cardiovascular disease due to jobrelated stress.

\section{Subjects and Methods}

\section{Subjects}

The study subjects were 140 male employees from a company that produces consumer goods, such as disposable diapers and sanitary napkins, located in Cheonan, South Korea. Only males were included in the study because the company employs only a small number of females. The employees work one of three shifts (morning, afternoon or night), and all three shifts were represented in the study population (Fig. 1). Self-administered questionnaires were used to gather information on demographic characteristics, job history, smoking history (never-, ex-, and current-smoker) and alcohol consumption. The study was approved by the Institutional Review Board at Dankook University Hospital, and each subject gave written informed consent.

\section{Measurement of job-related stress}

Job-related stress was measured using the job content questionnaire (JCQ), which contains 49 items based on the job strain model, which includes dimensions on quantitative psychological job demands (6 items), decision latitude $\left(9\right.$ items) and social support $(8 \text { items })^{13}$. Based on these parameters, subjects were placed in the high-strain group when psychological job demands were high and decision latitude was low and in the low-strain group when psychological job demands were low and decision latitude was high. Subjects were placed in the active group when psychological job demands and decision latitude were both high and in the passive group when both parameters were low. Ha et al. (2000) investigated the reliability of the Korean version of the JCQ and found that it offered a correlation coefficient higher than 0.4 when assessed using a test-retest method on psychological job demands (Chronbach's $\alpha=0.36$ ), decision latitude $(\alpha=0.69)$, and social support $(\alpha=0.76)^{14)}$.

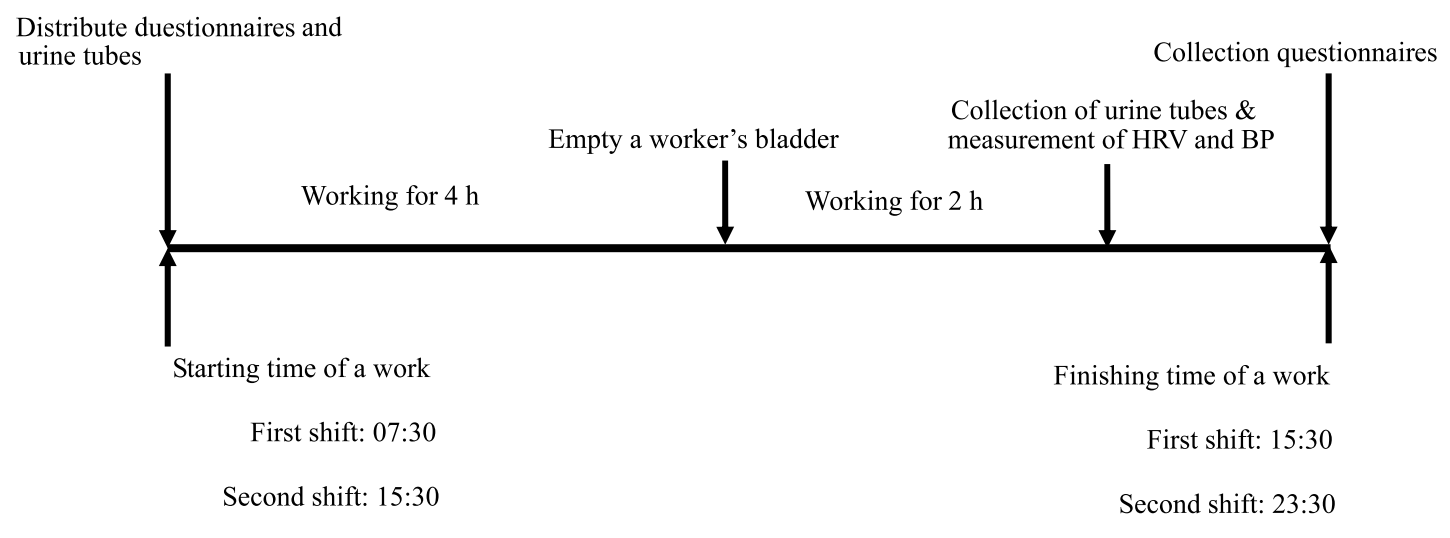

Fig. 1. Collection scheme for questionnaires and urine samples (140 male workers). 


\section{Measurement of heart rate variability $(H R V)$}

HRV was measured 3 times in each subject after the completion of different shifts (morning, afternoon and night). And we have used average level of HRV for statistical analysis. HRV was measured using a heart rate monitor (LRR-03, GMS Company, Limited, Japan) and analyzed using the MemCalc/BP analyzer program (Suwa Trust Co., Japan). Heart rate was measured for $5 \mathrm{~min}$ after a 5-min rest period to exclude the effects of shortterm activities. The 3-min data from the middle portion of the 5-min measurement was used in the analysis in order to ensure that the measurement was made from the regular respiration stage $(0.2 \mathrm{~Hz})$. After the evaluation of abnormal RR signals was automatically retrieved from the analysis program, subjects with more than $90 \%$ RR signals were chosen for the analysis. The power spectral density curve was calculated after calculating the normalto-normal $(\mathrm{NN})$ interval, which was the interval of the normal QRS complex. The spectral power was calculated within each frequency interval with $0.04-0.15 \mathrm{~Hz}$ as the low-frequency (LF) power and $0.15-0.40 \mathrm{~Hz}$ as the high-frequency (HF) power in the power spectral density curves ${ }^{15)}$.

Since LF power activities associated with both sympathetic and parasympathetic nervous activities and estimation of autonomic nervous activities from LF power is very complex, this study also use normalized LF (LFnu $=\mathrm{LF} /(\mathrm{LF}+\mathrm{HF}))$, normalized $\mathrm{HF}(\mathrm{HFnu}=\mathrm{HF} /(\mathrm{HF}+\mathrm{LF}))$ and $\mathrm{LF} / \mathrm{HF}$ ratio.

\section{Urine collection and catecholamine analysis}

Urine samples were collected from the subjects while they were working. Each employee was instructed to come to the test room at a specific time and asked to empty his bladder exactly $2 \mathrm{~h}$ before coming to the test room. Upon arrival at the test room, the subjects were asked to provide a urine sample. Urine collections and measurement of HRV from participants were conducted almost same time after work (Fig. 1).

The levels of epinephrine, norepinephrine, and dopamine in the urine were measured. The levels of stress hormones in the urine were analyzed using HPLC with an electrochemical detector ${ }^{16)}$. Urinary creatinine was measured and adjusted in order to control for the deviation that could appear among the subjects when using 2$\mathrm{h}$ urine samples. Furthermore, the urine stick test was performed immediately after the urine was collected to screen for urinary occult blood, urinary protein and urinary sugar in order to exclude subjects with renal function abnormalities.

\section{Statistical analysis}

Statistical comparisons between various groups were made by analysis of variance (ANOVA) followed by Duncan's post hoc test. ANOVA was performed in order to evaluate the differences in HRV and urinary catecholamines in the four groups determined according to the job strain model. ANOVA was also performed after stratification for the main variables, including duration of employment and age. Categorical variables such as marital status, smoking status and alcohol consumption were analyzed by Pearson's $\chi^{2}$ test. Pearson's correlation coefficient was used to evaluate correlations between job stress index and HRV. All statistical analyses were performed with the SPSS statistical package version 12.0 (SPSS Inc., Chicago, IL, USA).

\section{Results}

The mean age of the subjects was 29.1 (range: 25-44) $\mathrm{yr}$, and most of the subjects were under $35 \mathrm{yr}$ of age. The average seniority of the subjects was 62.5 months (range: 5.3-119.3 months). When the subjects were categorized according to the job strain model, $24(17.1 \%)$ subjects were placed in the low-strain group, 32 (22.9\%) were placed in the high-strain group, $64(45.7 \%)$ were placed in the passive group, and $20(14.3 \%)$ were placed in the active group. The active group had a longer seniority (mean: 66.6 months, range: 45.8-105.8) than the other groups, but these differences were not statistically significant ( $p=0.68$, by ANOVA) (Table 1$)$. The data from other categories, such as marital status, smoking habits and alcohol consumption, are summarized by job stress group in Table 1. More than half of the workers were married at the time of the study, and $53(41.4 \%)$ subjects had never been married. Approximately $77.3 \%$ of the workers were current smokers, and $64.0 \%$ of the workers drank alcohol for more than 2 months (Table 1). Job strain was not associated with marital status, smoking and dietary variable such as alcohol consumption (Table 1).

When the levels of urinary catecholamines, such as epinephrine, norepinephrine and dopamine, were compared in each group according to the job strain model, the highstrain group showed a slightly but not significantly higher level of urinary catecholamines when compared with the other groups. In addition, although there was no significant difference in HRV among the four job strain groups, HRV was higher in the high-strain group than in the low-strain group (Table 2). The LF/HF ratio, assessment of sympathetic activity, rose in the low-strain group (1.40) however were not statistically significant ( $p=0.60$, by ANOVA) (Table 2). When correlation analysis was performed to analyze the relationships between the job stress indices, such as decision latitude, psychological demands, social support and HRV including LF/HF ratio, no significant correlation was found between any of the 
Table 1. Selected characteristics of study subjects by job stress group

\begin{tabular}{|c|c|c|c|c|c|c|}
\hline Categories & Low strain & High strain & Passive & Active & Total & $p$ \\
\hline $\mathrm{N}$ & 24 & 32 & 64 & 20 & 140 & \\
\hline Age $($ yr old, mean \pm SD) & $29.0 \pm 2.2$ & $28.7 \pm 2.0$ & $29.2 \pm 2.6$ & $29.2 \pm 1.8$ & $29.1 \pm 2.3$ & $0.80^{\mathrm{a}}$ \\
\hline Seniority (months, mean \pm SD) & $62.7 \pm 13.7$ & $60.2 \pm 21.5$ & $62.3 \pm 15.1$ & $66.6 \pm 18.2$ & $62.5 \pm 16.8$ & $0.68^{\mathrm{a}}$ \\
\hline $\begin{array}{l}\text { Marital status (n, \%) } \\
\text { never married } \\
\text { married }\end{array}$ & $\begin{array}{c}7(5.5) \\
14(10.9)\end{array}$ & $\begin{array}{l}13(10.2) \\
16(12.5)\end{array}$ & $\begin{array}{l}26(20.3) \\
34(26.6)\end{array}$ & $\begin{array}{r}7(5.5) \\
11(8.6)\end{array}$ & $\begin{array}{l}53(41.4) \\
75(58.6)\end{array}$ & $0.84^{b}$ \\
\hline $\begin{array}{l}\text { Smoking (n, \%) } \\
\text { non-smoker } \\
\text { current-smoker }\end{array}$ & $\begin{array}{c}4(3.1) \\
17(13.3)\end{array}$ & $\begin{array}{c}7(5.5) \\
23(18.0)\end{array}$ & $\begin{array}{l}11(8.6) \\
47(36.7)\end{array}$ & $\begin{array}{r}7(5.5) \\
12(9.4)\end{array}$ & $\begin{array}{l}29(22.7) \\
99(77.3)\end{array}$ & $0.42^{b}$ \\
\hline $\begin{array}{l}\text { Drinking (n, \%) } \\
\quad<2 / \text { month } \\
\geq 2 / \text { month }\end{array}$ & $\begin{array}{r}7(5.6) \\
12(9.6)\end{array}$ & $\begin{array}{c}7(5.6) \\
22(17.6)\end{array}$ & $\begin{array}{l}24(19.2) \\
35(28.0)\end{array}$ & $\begin{array}{r}7(5.6) \\
11(8.8)\end{array}$ & $\begin{array}{l}45(36.0) \\
80(64.0)\end{array}$ & $0.49^{b}$ \\
\hline
\end{tabular}

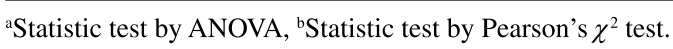

Table 2. Means ( \pm standard deviation) of heart rate variability and urinary catecholamine levels

\begin{tabular}{|c|c|c|c|c|c|c|c|}
\hline Categories & Low Strain & High strain & Passive & Active & Total & Range & $\begin{array}{c}p \\
\text { (ANOVA) }\end{array}$ \\
\hline $\mathrm{N}$ & 24 & 32 & 65 & 20 & 140 & & \\
\hline LF-HRV & $9.2 \pm 0.6$ & $9.3 \pm 1.0$ & $9.1 \pm 0.9$ & $9.1 \pm 1.1$ & $9.2 \pm 0.9$ & $5.3-11.2$ & 0.71 \\
\hline HF-HRV ${ }^{b}$ & $6.7 \pm 1.1$ & $6.8 \pm 1.0$ & $6.9 \pm 1.0$ & $7.0 \pm 1.5$ & $6.9 \pm 1.1$ & $1.8-9.5$ & 0.75 \\
\hline LFnu $^{c}$ & $0.6 \pm 0.0$ & $0.6 \pm 0.0$ & $0.6 \pm 0.0$ & $0.6 \pm 0.0$ & $0.6 \pm 0.0$ & $0.5-0.7$ & 0.40 \\
\hline $\mathrm{HFnu}^{\mathrm{d}}$ & $0.4 \pm 0.0$ & $0.4 \pm 0.0$ & $0.4 \pm 0.0$ & $0.4 \pm 0.0$ & $0.4 \pm 0.0$ & $0.3-0.5$ & 0.40 \\
\hline $\mathrm{LF} / \mathrm{HF}$ ratio $^{\mathrm{e}}$ & $1.4 \pm 0.2$ & $1.4 \pm 0.2$ & $1.3 \pm 0.2$ & $1.4 \pm 0.4$ & $1.4 \pm 0.2$ & $1.0-2.9$ & 0.60 \\
\hline Epinephrine $^{f}$ & $0.2 \pm 0.1$ & $0.2 \pm 0.1$ & $0.2 \pm 0.1$ & $0.1 \pm 0.1$ & $0.2 \pm 0.1$ & $0.0-0.7$ & 0.74 \\
\hline Norepinephrine $^{f}$ & $0.6 \pm 0.3$ & $0.7 \pm 0.5$ & $0.6 \pm 0.2$ & $0.6 \pm 0.2$ & $0.6 \pm 0.3$ & $0.3-3.0$ & 0.64 \\
\hline Dopamine $^{f}$ & $2.6 \pm 1.1$ & $2.6 \pm 1.7$ & $2.6 \pm 0.9$ & $2.6 \pm 1.1$ & $2.6 \pm 1.2$ & $1.1-11.5$ & 0.99 \\
\hline
\end{tabular}

${ }^{a}$ LF-HRV: natural log transformed low-frequency power heart rate variability $\left(\ln \left(\mathrm{ms}^{2} / \mathrm{Hz}\right)\right),{ }^{b} \mathrm{HF}-\mathrm{HRV}$ : natural $\log$ transformed high-frequency power heart rate variability $\left(\ln \left(\mathrm{ms}^{2} / \mathrm{Hz}\right)\right)$, ${ }^{C} \mathrm{LFnu}$ : normalized $\mathrm{LF},{ }^{\mathrm{d}} \mathrm{HFnu}$ : normalized $\mathrm{HF}$, ${ }^{\mathrm{e}} \mathrm{LF} / \mathrm{HF}$ ratio: index of cardiac sympathetic activity, ${ }^{\mathrm{T}}$ The units of metabolites are adjusted levels with urine creatinine ( $\mathrm{pmol} / \mathrm{mol}$ creatinine).

stress indices and HRV (Table 3). Furthermore, there was no significant correlation between these stress indices and the levels of urinary catecholamines. A significant negative correlation was found between the high-frequency band and the level of epinephrine (correlation coefficient $=-0.2, p<0.01$ ) (Table 3).

After work seniority was stratified according to quartile, the LF power was analyzed. The LF power in the subjects with the shortest seniority $(-48.5$ months, $n=27)$ was significantly different from that of the subjects in the other job stress groups $(p=0.04$, by ANOVA) (Table 4 , Fig. 2). The levels of log transfer LF power for job stress groups were compared individually by the post hoc analysis Duncan test and significant difference has been found between high strain and passive group in the shortest seniority (Table 4).

\section{Discussion}

Our results demonstrate that neither heart rate variability (HRV) nor urinary catecholamines are significantly associated with job stress in male manufacturing industry workers. There are several explanations for this lack of significance. Firstly, low statistical power due to the small sample size $(n=140)$ could have hampered resolution of the real association. Secondly, the Karasek model that was used to categorize job stress might not be sensitive enough to accurately indicate the stress level in Korean male manufacturing industry workers. Finally, the significant difference in the intra-group homogeneity analysis according to job seniority suggests that the present study included subjects who could adapt to highstress conditions relatively well, since only subjects who worked in shifts (selective survival) were included.

In previous studies, LF-power $\left[\ln \left(\mathrm{ms}^{2} / \mathrm{Hz}\right)\right]$ increases during mental stress in both animals and humans has been 
Table 3. Correlation coefficients between job stress index and heart rate variability, urinary catecholamine and duration of employment

\begin{tabular}{|c|c|c|c|c|c|c|c|c|c|c|c|}
\hline & DL & PJD & SS & $\mathrm{LN}(\mathrm{LF})$ & LN (HF) & $\mathrm{LF} / \mathrm{HF}$ & EPI & $\mathrm{NE}$ & DP & DUR & Age \\
\hline DL & & $0.24^{\mathrm{a}}$ & $0.31^{\mathrm{b}}$ & -0.12 & -0.05 & 0.04 & 0.07 & 0.01 & 0.02 & $0.21^{\mathrm{a}}$ & 0.09 \\
\hline PJD & & & -0.08 & -0.07 & -0.10 & 0.12 & 0.11 & 0.07 & 0.05 & -0.01 & -0.05 \\
\hline SS & & & & -0.02 & -0.08 & 0.14 & -0.02 & -0.05 & -0.03 & -0.07 & -0.09 \\
\hline LN (LF) & & & & & $0.64^{b}$ & $-0.22^{\mathrm{a}}$ & -0.05 & 0.00 & -0.00 & $-0.30^{\mathrm{b}}$ & $-0.18^{\mathrm{a}}$ \\
\hline $\mathrm{LN}(\mathrm{HF})$ & & & & & & $-0.82^{\mathrm{b}}$ & $-0.19^{a}$ & $-0.19^{\mathrm{a}}$ & -0.15 & $-0.21^{\mathrm{a}}$ & -0.17 \\
\hline LF/HF & & & & & & & $0.17^{\mathrm{a}}$ & $0.19^{\mathrm{a}}$ & 0.12 & 0.11 & 0.08 \\
\hline EPI & & & & & & & & $0.73^{b}$ & $0.66^{\mathrm{b}}$ & 0.04 & 0.11 \\
\hline $\mathrm{NE}$ & & & & & & & & & $0.85^{\mathrm{b}}$ & 0.00 & 0.08 \\
\hline $\mathrm{DP}$ & & & & & & & & & & -0.04 & 0.01 \\
\hline DUR & & & & & & & & & & & $0.52^{\mathrm{b}}$ \\
\hline
\end{tabular}

${ }^{\mathrm{a}} p<0.05,{ }^{\mathrm{b}} p<0.01$.

DL, decision latitude; PJD, psychological job demand; SS, social support; LN (LF), natural log transformed low-frequency power of heart rate variability; LN (HF), natural log transformed high-frequency power of heart rate variability; LF/HF, index of cardiac sympathetic activity; EPI, epinephrine in urine; NE, norepinephrine in urine; DP, dopamine in urine; DUR, work duration.

described $^{17,18)}$. As well, exposure to high levels of stress in the workplace increases the log LF power $\left[\ln \left(\mathrm{ms}^{2} / \mathrm{Hz}\right)\right]^{9)}$. A significant reduction in HRV was noted in the low control group in a study of healthy mid-aged male $^{3)}$, and HRV was significantly lower in the high strain group than in the low strain group in shipyard male work$\mathrm{ers}^{7)}$. In this study, only LF-HRV was significantly higher in the high-strain group of subjects with a shorter duration of employment ( $<48.5$ months) when the data was stratified by seniority in this study. However, the normalized spectral indices (LFnu and HFnu) were not associated with job strain. This finding indicates that the autonomic nervous activity that directs the LF power was theoretically higher in the high-strain group in this study. Absolute powers are fundamentally influenced by the amount of total power, which may significantly vary interand intra-individually when heart rate changes, making them hard to compare and interpret. Normalization eliminates inter- and intra subject variability in the raw HRV spectral power ${ }^{19)}$. Therefore, LFnu and HFnu are more reliable and appropriate indexes for estimating autonomic activity than $\mathrm{LF}^{19}$ ). However, the biological mechanism(s) by which such psychosocial stressors in workplace has been elusive.

Although spectral analyses of HRV and catecholamine are useful for a variety of physiological stresses, no correlation was presently found between normalized spectral indices, catecholamine and job-stress. This might reflect the low statistical power of the study approach. The present results imply the possibility that job stress affects the risk of developing cardiovascular disease only in subjects with the least seniority. However, the aforementioned potential limitations prevent generalization of this suggestion. Furthermore, we expect that job stress-related changes in autonomic nerve activity might affect workers of all levels of seniority if a large-scaled, prospective study were conducted. This is only an assumption, and more studies must be conducted. In addition, it is impossible to conduct further analyses in each seniority level group because the sample size is too small. Thus, a largescaled prospective study is necessary.

The present study indicates an influence of job seniority on the relationship between LF power and job-related stress. The association between LF power and job-related stress was only found in the group of workers with the least seniority, whose limited working period could blunt their stress adapting coping skills, which are gained with time. But, presently, LF power correlated positively with HF power, meaning that increasing parasympathetic nervous activity might increase LF power. Therefore, our results should be interpreted very carefully and further studies are needed. Our study analyzed the relationship between job stress and both LF and HF. There was no significant difference in HF among the four job strain groups. In addition, analysis after stratification by work seniority showed no significant difference in HF. Actually, LF power is associated with both sympathetic and parasympathetic nerve activity, and estimation of autonomic nerve activity is very complex. More sophisticated data sampling, including that from a clinical setting, is recommended for future studies.

The level of urinary catecholamines is significantly correlated with various stressful job situations, such as those experienced by police officers ${ }^{20)}$, glass manufacturers ${ }^{21}$, and female nurses ${ }^{22}$. Occupationally-induced reactivity in the levels of urinary catecholamines have been documented in bus drivers ${ }^{12)}$ and truck drivers ${ }^{11)}$. In the latter study, excretion rates of epinephrine, and especially 
Table 4. Mean ( \pm standard deviation) of log transfer low-frequency power of heart rate variability (LF power), HFnu, LFnu, LF/HF, age, smoking status and alcohol consumption for job stress group stratified by duration of employment

\begin{tabular}{|c|c|c|c|c|c|c|}
\hline Seniority (months) & Low strain & High strain & Passive & Active & Total & $p$ \\
\hline$\sim \leq 48.5$ & & & & & & \\
\hline $\mathrm{N}$ & 5 & 7 & 12 & 3 & 27 & \\
\hline LF power & $9.3 \pm 0.5$ & $10.0 \pm 0.4^{\mathrm{a}}$ & $9.0 \pm 0.9$ & $9.3 \pm 0.5$ & $9.3 \pm 0.8$ & $0.04^{\mathrm{b}}$ \\
\hline LFnu & $0.6 \pm 0.0$ & $0.6 \pm 0.0$ & $0.6 \pm 0.0$ & $0.5 \pm 0.0$ & $0.6 \pm 0.0$ & $0.49^{\mathrm{b}}$ \\
\hline HFnu & $0.4 \pm 0.0$ & $0.4 \pm 0.0$ & $0.4 \pm 0.0$ & $0.5 \pm 0.0$ & $0.4 \pm 0.0$ & $0.49^{b}$ \\
\hline $\mathrm{LF} / \mathrm{HF}$ & $1.4 \pm 0.1$ & $1.3 \pm 0.1$ & $1.3 \pm 0.2$ & $1.2 \pm 0.2$ & $1.3 \pm 0.2$ & $0.65^{b}$ \\
\hline Age $(y r$, mean $\pm S D)$ & $26.7 \pm 0.6$ & $27.3 \pm 1.5$ & $28.3 \pm 1.9$ & $28.7 \pm 2.1$ & $27.9 \pm 1.8$ & $0.32^{\mathrm{b}}$ \\
\hline \multicolumn{7}{|l|}{ Smoking $(\%)$} \\
\hline non-smoker & 4.0 & 8.0 & 0.0 & 4.0 & 16.0 & \\
\hline smoker & 8.0 & 20.0 & 48.0 & 8.0 & 84.0 & $0.22^{\mathrm{c}}$ \\
\hline \multicolumn{7}{|l|}{ Drinking (\%) } \\
\hline$<2 /$ month & 4.2 & 0.0 & 16.7 & 8.3 & 29.2 & \\
\hline$\geq 2 /$ month & 4.2 & 29.2 & 33.3 & 4.2 & 70.8 & $0.14^{\mathrm{c}}$ \\
\hline \multicolumn{7}{|l|}{ Q2: $48.5 \sim \leq 60.5$} \\
\hline $\mathrm{N}$ & 5 & 4 & 16 & 7 & 32 & \\
\hline LF power & $9.3 \pm 0.8$ & $8.9 \pm 0.5$ & $9.3 \pm 0.8$ & $9.4 \pm 0.5$ & $9.3 \pm 0.7$ & $0.72^{b}$ \\
\hline LFnu & $0.6 \pm 0.0$ & $0.6 \pm 0.0$ & $0.6 \pm 0.0$ & $0.5 \pm 0.0$ & $0.6 \pm 0.0$ & $0.59^{b}$ \\
\hline HFnu & $0.4 \pm 0.0$ & $0.4 \pm 0.0$ & $0.4 \pm 0.0$ & $0.5 \pm 0.0$ & $0.4 \pm 0.0$ & $0.59^{b}$ \\
\hline LF/HF & $1.4 \pm 0.2$ & $1.5 \pm 0.3$ & $1.3 \pm 0.2$ & $1.3 \pm 0.1$ & $1.4 \pm 0.2$ & $0.50^{\mathrm{b}}$ \\
\hline Age $(y r$, mean $\pm S D)$ & $29.0 \pm 2.1$ & $30.0 \pm 3.2$ & $28.6 \pm 1.1$ & $28.3 \pm 0.8$ & $28.8 \pm 1.6$ & $0.36^{\mathrm{b}}$ \\
\hline \multicolumn{7}{|l|}{ Smoking $(\%)$} \\
\hline non-smoker & 0.0 & 3.1 & 6.3 & 9.4 & 18.8 & \\
\hline smoker & 15.6 & 9.4 & 43.8 & 12.5 & 81.3 & $0.23^{\circ}$ \\
\hline \multicolumn{7}{|l|}{ Drinking (\%) } \\
\hline$<2 /$ month & 6.5 & 9.7 & 32.3 & 6.5 & 54.8 & \\
\hline$\geq 2 /$ month & 9.7 & 0.0 & 19.4 & 16.1 & 45.2 & $0.16^{\circ}$ \\
\hline \multicolumn{7}{|l|}{ Q3: $60.5 \sim 51.5$} \\
\hline $\mathrm{N}$ & 5 & 7 & 14 & 1 & 27 & \\
\hline LF power & $9.1 \pm 0.5$ & $9.6 \pm 0.9$ & $9.4 \pm 0.6$ & $9.7 \pm 0.0$ & $9.4 \pm 0.7$ & $0.58^{\mathrm{b}}$ \\
\hline LFnu & $0.6 \pm 0.0$ & $0.6 \pm 0.0$ & $0.6 \pm 0.0$ & $0.5 \pm 0.0$ & $0.6 \pm 0.0$ & $0.69^{\mathrm{b}}$ \\
\hline HFnu & $0.4 \pm 0.0$ & $0.4 \pm 0.0$ & $0.4 \pm 0.0$ & $0.5 \pm 0.0$ & $0.4 \pm 0.0$ & $0.69^{b}$ \\
\hline $\mathrm{LF} / \mathrm{HF}$ & $1.5 \pm 0.1$ & $1.4 \pm 0.1$ & $1.4 \pm 0.2$ & $1.4 \pm 0.0$ & $1.4 \pm 0.1$ & $0.70^{b}$ \\
\hline Age $(y r$, mean $\pm S D)$ & $30.0 \pm 2.6$ & $28.6 \pm 0.8$ & $29.2 \pm 1.3$ & $28.0 \pm 0.0$ & $29.2 \pm 1.5$ & $0.38^{b}$ \\
\hline \multicolumn{7}{|l|}{ Smoking $(\%)$} \\
\hline non-smoker & 0.0 & 7.7 & 19.2 & 0.0 & 26.9 & \\
\hline smoker & 19.2 & 19.2 & 30.8 & 3.8 & 73.1 & $0.38^{\circ}$ \\
\hline \multicolumn{7}{|l|}{ Drinking (\%) } \\
\hline$<2 /$ month & 0.0 & 8.0 & 8.0 & 0.0 & 16.0 & \\
\hline$\geq 2 /$ month & 16.0 & 20.0 & 44.0 & 4.0 & 84.0 & $0.62^{\circ}$ \\
\hline \multicolumn{7}{|l|}{ Q4: 71.5< } \\
\hline $\mathrm{N}$ & 5 & 8 & 15 & 6 & 35 & \\
\hline LF power & $9.0 \pm 0.9$ & $9.2 \pm 1.1$ & $8.8 \pm 1.1$ & $8.6 \pm 1.9$ & $8.9 \pm 1.2$ & $0.84^{b}$ \\
\hline LFnu & $0.6 \pm 0.0$ & $0.6 \pm 0.0$ & $0.6 \pm 0.0$ & $0.6 \pm 0.1$ & $0.6 \pm 0.0$ & $0.79^{b}$ \\
\hline HFnu & $0.4 \pm 0.0$ & $0.4 \pm 0.0$ & $0.4 \pm 0.0$ & $0.4 \pm 0.1$ & $0.4 \pm 0.0$ & $0.79^{\mathrm{b}}$ \\
\hline $\mathrm{LF} / \mathrm{HF}$ & $1.4 \pm 0.2$ & $1.4 \pm 0.2$ & $1.3 \pm 0.2$ & $1.5 \pm 0.7$ & $1.4 \pm 0.3$ & $0.63^{\mathrm{b}}$ \\
\hline Age $(y r$, mean $\pm S D)$ & $29.0 \pm 2.6$ & $30.3 \pm 2.0$ & $31.2 \pm 4.2$ & $30.8 \pm 2.1$ & $30.6 \pm 3.2$ & $0.66^{\mathrm{b}}$ \\
\hline \multicolumn{7}{|l|}{ Smoking $(\%)$} \\
\hline non-smoker & 7.1 & 7.1 & 7.1 & 10.7 & 32.1 & \\
\hline smoker & 10.7 & 14.3 & 32.1 & 10.7 & 67.9 & $0.57^{\circ}$ \\
\hline \multicolumn{7}{|l|}{ Drinking (\%) } \\
\hline$<2 /$ month & 10.7 & 7.1 & 17.9 & 10.7 & 46.4 & \\
\hline$\geq 2 /$ month & 7.1 & 14.3 & 25.0 & 7.1 & 53.6 & $0.74^{\circ}$ \\
\hline
\end{tabular}

${ }^{\mathrm{a}} p<0.05$ (Duncan test for post hoc analysis) vs Passive group, ${ }^{\mathrm{b}}$ Test by ANOVA, ${ }^{\mathrm{c}}$ Statistic test by Pearson's $\chi^{2}$ test, LFnu, normalized LF; HFnu, normalized HF. 


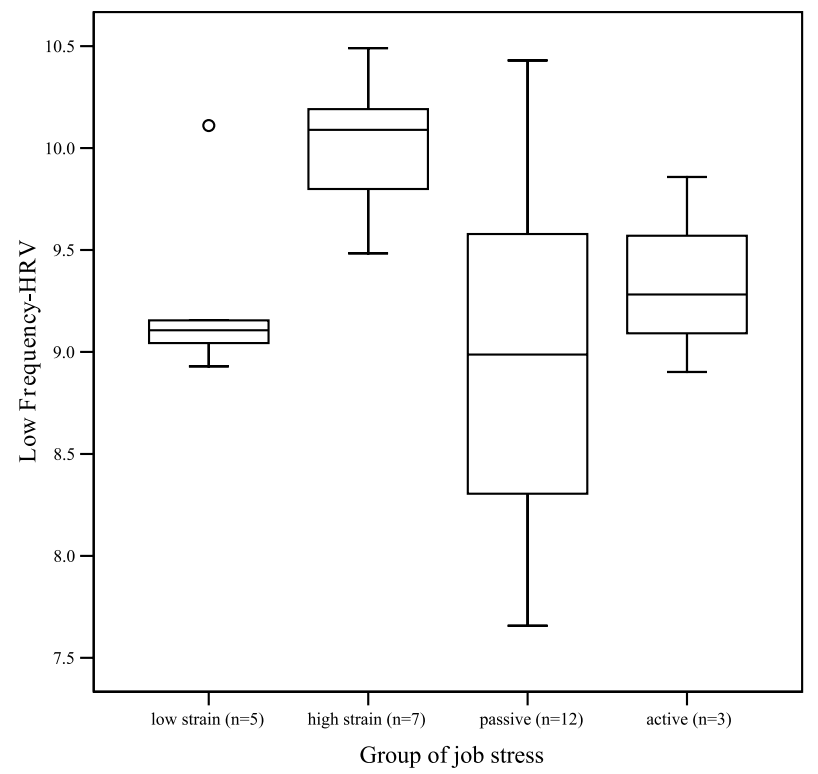

Fig. 2. Box plot of low-frequency power of heart rate variability (LF-HRV) for job stress among employees with a short duration of employment ( $\leq 48.5$ months) $(n=27, p=0.04$ by ANOVA).

Boxes encompass the 25th-75th percentiles, middle lines: the medians, whiskers: the 10th-90th percentiles and a circle $(\bigcirc)$ represents values beyond the 90th percentiles.

norepinephrine, during the workday were higher than those found in earlier studies of professional drivers, and the recovery period after the completion of daily work was relatively insufficient ${ }^{11}$. A recent biomarker study of 106 Japanese hospital workers with greater psychological job stress reported lower brain-derived neurotrophic factor levels and higher plasma 3-methoxy-4hydroxyphenylglycol levels than in workers suffering from less job stress ${ }^{23)}$. However, presently there was no significant correlation between job-related stress and the levels of urinary catecholamines. There are two potential explanations for this discrepancy. Firstly, we obtained measurements of urinary catecholamines three times during each work shift, which may have limited measurement of urine samples because we collected point urine samples rather than $24 \mathrm{~h}$ urine samples, and the time points of sample collection differed by more than $2 \mathrm{~h}$ due to differences in the subjects' individual work schedules. A second explanation is that the number of subjects included in the study was small.

The study subjects were instructed not to smoke, engage in extra-ordinary physical activity or drink any beverages before the autonomic nerve function measurement in order to minimize the effects of daily activity and tastes. Including these factors, data on possible major confounding factors, such as stressors of daily life and caffeine intake, were not collected nor assessed. This is one more limitation of this study. Data on these factors should be collected and controlled in the next study.

Although this study population was composed solely of Korean workers, we did not assume that Korean workers might experience different forms of job stress related to autonomic nerve activity than those experienced by workers in other countries. The inclusion of only Korean workers merely reflects the domestic nature of the study. We cannot extrapolate the results of this study to workers of other countries, including those from other Asian countries. Thus, a well-designed future study involving subjects of varying ethnicity is needed.

The cross-sectional nature of the study makes it difficult to understand the causal relationships among the variables. Thus, further studies are needed to investigate the relationship between stress and autonomic activity according to level of seniority. Furthermore, the development of job stress indices that reflect individual differences within similar groups and the development and evaluation of reliable job stress indices that are applicable to Korean workers would be interesting subjects for future study.

\section{Acknowledgement}

This research was supported by BRL (Basic Research Laboratory) program through the National Research Foundation of Korea funded by the Ministry of Education, Science and Technology (2009-0087452).

\section{References}

1) Peter R, Siegrist J, Hallqvist J, Reuterwall C, Theorell $\mathrm{T}$ (2002) Psychosocial work environment and myocardial infarction: improving risk estimation by combining two complementary job stress models in the SHEEP Study. J Epidemiol Community Health 56, 294-300.

2) Bunker SJ, Colquhoun DM, Esler MD, Hickie IB, Hunt D, Jelinek VM, Oldenburg BF, Peach HG, Ruth D, Tennant CC, Tonkin AM (2003) "Stress" and coronary heart disease: psychosocial risk factors. Med J Aust 178, 272-6.

3) Collins SM, Karasek RA, Costas K (2005) Job strain and autonomic indices of cardiovascular disease risk. Am J Ind Med 48, 182-93.

4) Sztajzel J (2004) Heart rate variability: a noninvasive electrocardiographic method to measure the autonomic nervous system. Swiss Med Wkly 134, 514-22.

5) Towa S, Kuwahara M, Tsubone H (2004) Characteristics of autonomic nervous function in Zucker-fatty rats: investigation by power spectral analysis of heart rate variability. Exp Anim 53, 137-44.

6) Rovere MTL, Bigger JJT, Marcus FI, Mortara A, Schwartz PJ (1998) Baroreflex sensitivity and heart-rate variability in prediction of total cardiac mortality after myocardial infarction. Lancet 351, 478-84.

7) Kang MG, Koh SB, Cha BS, Park JK, Woo JM, Chang 
SJ (2004) Association between job stress on heart rate variability and metabolic syndrome in shipyard male workers. Yonsei Med J 45, 838-46.

8) Pagani M, Mazzuero G, Ferrari A, Liberati D, Cerutti S, Vaitl D, Tavazzi L, Malliani A (1991a) Sympathovagal interaction during mental stress. A study using spectral analysis of heart rate variability in healthy control subjects and patients with a prior myocardial infarction. Circulation 83, II43-51.

9) Amelsvoort LGPMv, Schouten EG, Maan AC, Swenne CA, Kok FJ (2000) Occupational determinants of heart rate variability. Int Arch Occup Environ Health 73, 255-62.

10) Sloan RP, Shapiro PA, Bagiella E, Bigger JT, Jr., Lo ES, Gorman JM (1996) Relationships between circulating catecholamines and low frequency heart period variability as indices of cardiac sympathetic activity during mental stress. Psychosom Med 58, 25-31.

11) van der Beek AJ, Meijman TF, Frings-Dresen MH, Kuiper JI, Kuiper S (1995) Lorry drivers' work stress evaluated by catecholamines excreted in urine. Occup Environ Med 52, 464-9.

12) Sluiter JK, van der Beek AJ, Frings-Dresen MH (1998) Work stress and recovery measured by urinary catecholamines and cortisol excretion in long distance coach drivers. Occup Environ Med 55, 407-13.

13) Karasek R, Brisson C, Kawakami N, Houtman I, Bongers P, Amick B (1998) The Job Content Questionnaire (JCQ): an instrument for internationally comparative assessments of psychosocial job characteristics. J Occup Health Psychol 3, 322-55.

14) Ha M, Jang SJ, Cho JJ, Ju YS (2001) Standardization and development of Korean version of job stress measurement method-The project of job stress and health effects in Korean. Occupational safety \& Health Research Institute, KOSHA, Incheon.

15) Huikuri HV, Valkama JO, Airaksinen KE, Seppanen T, Kessler KM, Takkunen JT, Myerburg RJ (1993) Frequency domain measures of heart rate variability before the onset of nonsustained and sustained ventricular tachycardia in patients with coronary artery disease. Circulation 87, 1220-8.

16) Peaston RT (1988) Routine determination of urinary free catecholamines by high-performance liquid chromatography with electrochemical detection. J Chromatogr 424, 263-72.

17) Pagani M, Rimoldi O, Pizzinelli P, Furlan R, Crivellaro W, Liberati D, Cerutti S, Malliani A (1991b) Assessment of the neural control of the circulation during psychological stress. J Auton Nerv Syst 35, 33-41.

18) Schubert C, Lambertz $M$, Nelesen RA, Bardwell W, Choi JB, Dimsdale JE (2009) Effects of stress on heart rate complexity - a comparison between short-term and chronic stress. Biol Psychol 80, 325-32.

19) Burr RL (2007) Interpretation of normalized spectral heart rate variability indices in sleep research: a critical review. Sleep 30, 913-9.

20) Piercecchi-Marti MD, Leonetti G, Pelissier AL, Conrath J, Cianfarani F, Valli M (1999) Evaluation of biological stress markers in police officers. Med Law 18, 125-44.

21) Vangelova K, Deyanov C, Velkova D, Ivanova M, Stanchev V (2002) The effect of heat exposure on cortisol and catecholamine excretion rates in workers in glass manufacturing unit. Cent Eur J Public Health 10, 149-52.

22) Goldstein IB, Shapiro D, Chicz-DeMet A, Guthrie D (1999) Ambulatory blood pressure, heart rate, and neuroendocrine responses in women nurses during work and off work days. Psychosom Med 61, 387-96.

23) Mitoma M, Yoshimura R, Sugita A, Umene W, Hori H, Nakano H, Ueda N, Nakamura J (2008) Stress at work alters serum brain-derived neurotrophic factor (BDNF) levels and plasma 3-methoxy-4-hydroxyphenylglycol (MHPG) levels in healthy volunteers: BDNF and MHPG as possible biological markers of mental stress? Prog Neuropsychopharmacol Biol Psychiatry 32, 679-85. 